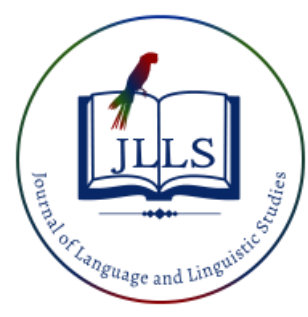

Available online at www.jlls.org

JOURNAL OF LANGUAGE

AND LINGUISTIC STUDIES

ISSN: 1305-578X

Journal of Language and Linguistic Studies, 17(4), 1873-1887; 2021

\title{
Mandarin adaptations of voiced alveolar fricative [z] in English loanwords
}

\begin{abstract}
Wei Wang a iD
\section{APA Citation:}

${ }^{a}$ College of Humanities, Jilin University, Changchun, China

Wang, W. (2021). Mandarin adaptations of voiced alveolar fricative [z] in English loanwords. Journal of Language and Linguistic Studies, 17(4), 1873-1887. Doi: 10.52462/jlls.136

Submission Date:07/06/2021

Acceptance Date:20/08/2021
\end{abstract}

\begin{abstract}
This paper explores the adaptation of English voiced fricative $[\mathrm{z}]_{\mathrm{E}}$ into Mandarin. The principal findings are that the adaptation of $[\mathrm{z}]_{\mathrm{E}}$ depends on its position in the source word. If $[\mathrm{z}]_{\mathrm{E}}$ occupies the word initial or middle position, it tends to be borrowed as Mandarin $[\mathrm{ts}]_{\mathrm{M}}$ or $[\mathrm{s}]_{\mathrm{M}}$. If $[\mathrm{z}]_{\mathrm{E}}$ is in the ending position, more variations would be observed as it may correspond to $[\mathrm{ts}]_{\mathrm{M}},[\mathrm{s}]_{\mathrm{M}},[\mathrm{ts}]_{\mathrm{M}}$ or $[\mathrm{s}]_{\mathrm{M}}$. Moreover, adapting $[\mathrm{z}]_{\mathrm{E}}$ into Mandarin is also heavily influenced by the orthography. The English $[\mathrm{z}]_{\mathrm{E}}$ can be spelled with $\langle\mathrm{s}\rangle$ or $\langle\mathrm{z}\rangle$. The letters of $\langle\mathrm{s}\rangle$ and $\langle\mathrm{z}\rangle$ are also listed in Mandarin Pinyin, a Romanization system that transcribes the sounds of Chinese characters using Roman alphabets. Specifically, $\left\langle\mathrm{s}>\right.$ is pronounced as $[\mathrm{s}]_{\mathrm{M}}$, while $[\mathrm{z}]$ is pronounced as $[\mathrm{ts}]_{\mathrm{M}}$. It turns out that $[\mathrm{s}]_{\mathrm{M}}$ sounds different from $[\mathrm{z}]_{\mathrm{E}}$, while $[\mathrm{ts}]_{\mathrm{M}}$ is perceptually similar to $[\mathrm{z}]_{\mathrm{E}}$. Generally, there emerged two major adaptation patterns, that is, $\langle\mathrm{z}\rangle[\mathrm{z}]_{\mathrm{E}} \rightarrow\langle\mathrm{z}\rangle[\mathrm{ts}]_{\mathrm{M}}$ and $\langle\mathrm{s}\rangle[\mathrm{z}]_{\mathrm{E}} \rightarrow\langle\mathrm{s}\rangle[\mathrm{s}]_{\mathrm{M}}$. The latter is based on the spelling similarity, rather than perceptual similarity. It is therefore concluded that the loanword adaptation is not only determined by the speech perception, phonology and legitimacy of sound structures, but also systematically interfered with the orthography, that is, the source-loan spelling similarity.
\end{abstract}

Keywords: loanword adaptation; orthography; perceptual similarity; phonological similarity; sound structure

\section{Introduction}

Loanwords, also referred to as lexical borrowings, are words adapted from the source language (SL) into the borrowing language (BL) (Kang, 2013). During the adaptation, the non-native (SL) segments and structures will be modified according to perceptual and phonological similarity, which are regarded as grammatical factors (Peperkamp \& Dupoux, 2003; Boersma \& Hamann, 2009; Paradis \& Tremblay, 2009; Hsieh, 2014; Chang, 2013; Chen \& Lu, 2020). However, the extra-grammatical factors, such as orthography, can also influence the adaptation result (Vendelin \& Peperkamp, 2006; Detey \& Nespoulous, 2008; Kang, 2009; Daland et al., 2015; Hamann \& Colombo, 2017). Take Mandarin adaptations of English voiced alveolar fricative $[\mathrm{z}]_{\mathrm{E}}$ as an example, it is mainly adapted into Mandarin as $[\mathrm{s}]_{\mathrm{M}}$ or $[\mathrm{ts}]_{\mathrm{M}}$, and occasionally borrowed as other fricatives and affricates ("[]" is used to represent sounds; a subscript $M$ is attached to mark the Mandarin form; a subscript $E$ is attached to mark the English form;). It is argued in this paper that such variations are attributed to the interaction of perceptual, phonological, structural and orthographic factors.

\footnotetext{
${ }^{1}$ Corresponding author.

E-mail address: weiw18@mails.jlu.edu.cn
} 


\subsection{Literature review}

\subsubsection{Background in English and Mandarin fricatives and affricates}

English and Mandarin fricatives and affricates are shown in Table 1 \& 2, respectively. English adopts a deep orthography. One English phoneme may correspond to different letters or letter units, and vice versa. English $[\mathrm{z}]_{\mathrm{E}}$ is flexibly written by either $\langle\mathrm{s}\rangle$ or $\langle\mathrm{z}\rangle$, and it is perceptually similar to Mandarin $[\mathrm{ts}]_{\mathrm{M}}$. From perceptual account, the $[\mathrm{z}]_{\mathrm{E}} \rightarrow[\mathrm{ts}]_{\mathrm{M}}$ correspondence can be regarded as a default matching in the adaptation of English $[\mathrm{z}]_{\mathrm{E}}$ into Mandarin. In contrast, Mandarin lacks voiced fricatives and does not have the sound of $[\mathrm{z}]$ in its sound inventory. The letter-sound correspondence is rather fixed as the sound of $[\mathrm{ts}]_{\mathrm{M}}$ is always spelled with $\langle\mathrm{z}\rangle$, and the sound of $[\mathrm{s}]_{\mathrm{M}}$ is often spelled with $\langle\mathrm{s}\rangle$. More examples concerning the English and Mandarin grapheme-to-phoneme correspondence are presented in (1). Mandarin also has strict phonotactic constraints. Mandarin fricatives and affricates of $[\mathrm{s}]_{\mathrm{M}}$ and $[\mathrm{ts}]_{\mathrm{M}}$ are forbidden to co-occur with the high front vowel [i].

Table 1. English fricatives and affricates

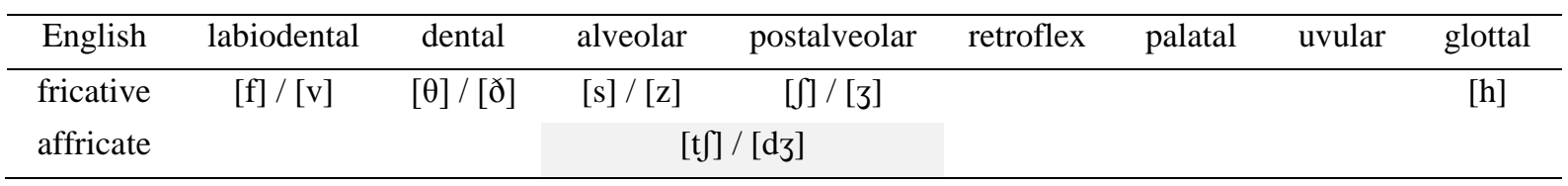

Table 2. Mandarin fricatives and affricates

\begin{tabular}{|c|c|c|c|c|c|c|c|}
\hline Mandarin & labiodental & dental & alveolar & postalveolar & palatal & uvular & glottal \\
\hline fricative & [f] & & [s] & [s] & [6] & \multirow[t]{2}{*}[\mathrm{x}]{} & \\
\hline affricate & & \multicolumn{4}{|c|}{$[\mathrm{ts}] /\left[\mathrm{ts}^{\mathrm{h}}\right] /[\mathrm{ts}] /\left[\mathrm{ts}^{\mathrm{h}}\right] /[\mathrm{t} \mathrm{t}] /\left[\mathrm{t}^{\mathrm{h}}\right]$} & & \\
\hline
\end{tabular}

(1) English sounds Corresponding graphem

$\begin{array}{cc}{[\mathrm{f}]_{\mathrm{E}}} & <\mathrm{f}>/<\mathrm{ph}> \\ {[\mathrm{v}]_{\mathrm{E}}} & <\mathrm{v}> \\ {[\theta]_{\mathrm{E}}} & <\mathrm{th}> \\ {\left[{ }_{\mathrm{E}}\right]_{\mathrm{E}}} & <\mathrm{th}> \\ {[\mathrm{s}]_{\mathrm{E}}} & <\mathrm{s}> \\ {[\mathrm{z}]_{\mathrm{E}}} & <\mathrm{s}>/<\mathrm{z}> \\ {\left[\int\right]_{\mathrm{E}}} & <\mathrm{sh}> \\ {[3]_{\mathrm{E}}} & <\mathrm{s}> \\ {[\mathrm{h}]_{\mathrm{E}}} & <\mathrm{h}> \\ [\mathrm{t}]]_{\mathrm{E}} & <\mathrm{ch}> \\ {[\mathrm{d} 3]_{\mathrm{E}}} & <\mathrm{dg}>\end{array}$

\begin{tabular}{|cc} 
Mandarin sounds & Corresponding grapheme \\
{$[\mathrm{f}]_{\mathrm{M}}$} & $<\mathrm{f}>$ \\
{$[\mathrm{s}]_{\mathrm{M}}$} & $<\mathrm{s}>$ \\
{$[\mathrm{s}]_{\mathrm{M}}$} & $<\mathrm{sh}>$ \\
{$[\mathrm{c}]_{\mathrm{M}}$} & $<\mathrm{x}>$ \\
{$[\mathrm{x}]_{\mathrm{M}}$} & $<\mathrm{h}>$ \\
{$[\mathrm{ts}]_{\mathrm{M}}$} & $<\mathrm{z}>$ \\
{$\left[\mathrm{ts}^{\mathrm{h}}\right]_{\mathrm{M}}$} & $<\mathrm{c}>$ \\
{$[\mathrm{ts}]_{\mathrm{M}}$} & $<\mathrm{zh}>$ \\
{$\left[\mathrm{ts}^{\mathrm{h}}\right]_{\mathrm{M}}$} & $<\mathrm{ch}>$ \\
{$[\mathrm{tc}]_{\mathrm{M}}$} & $<\mathrm{j}>$ \\
{$\left[\mathrm{tc}^{\mathrm{h}}\right]_{\mathrm{M}}$} & $<\mathrm{q}>$
\end{tabular}

\subsubsection{The role of orthography in loanword adaptation}

According to the previous loanword studies, orthography use to be regarded as an extragrammatical factor that needs to be excluded before doing the loanword phonology analysis. However, borrowers are not necessarily fully competent bilinguals who have access to both BL and SL phonology. For those without or with insufficient SL learning experience, they may be guided by the 
orthography and do the reading adaptation by using the BL grapheme-to-phoneme correspondence (henceforth "GPC") rules. The BL GPC rules are more frequently adopted when borrowers are uncertain or unknown about the phonemic identity of the source word. Consequently, a new adaptation pattern would emerge as a result of conforming to the source-loan orthographic alignment. The surface forms of orthography-based adaptation could be different from those driven by phonetic and phonological mapping (Vendelin \& Peperkamp, 2006; Kang, 2009; Hamann \& Colombo, 2017).

Vendelin \& Peperkamp firstly designed a psycholinguistic experiment to examine the adaptation of eight English monophthongs into French. For instance, the English vowel /u/ could be written as $<00>$, and its closest sound in French also corresponds to $/ \mathrm{u} /($ " $<>$ " is used to represent written forms; " /// is used to represent phonemes). However, the written form of $\langle\mathrm{oo}\rangle$ would be pronounced as $/ \mathrm{s} /$ or $/ \mathrm{s} /$ in French. When borrowing English containing $\langle 00\rangle$, French adapters are faced with two options, either the perception-based adaptation or the orthography-based adaptation as guided by the spelling similarity. The results indicated that there was a strong orthography effect in French adaptation of English single vowels. Participants of French native speakers were provided with the stimuli under different modalities, including auditory and mixed condition (visual + auditory). They found that an additional exposure of written forms would significantly induce participants to make more adaptations influenced by the orthography, instead of perception and phonology.

Kang (2009) also confirmed a significant orthography effect in Korean adaptation of English morphemic /z/ and non-morphemic /z/ in the 1930s. The English morphemic / $\mathrm{z} /$ is a plural or possessive marker, and tends to correspond to [s] or $\left[\mathrm{s}^{*}\right]$ when adapted into Korean, such as beans $[\text { bi:nz }]_{\mathrm{E}} \rightarrow[\text { pinsi }]_{\mathrm{K}}$, motors $[\text { movtəz }]_{\mathrm{E}} \rightarrow\left[\mathrm{mo}: \mathrm{t}^{\mathrm{h}} \Lambda \mathrm{si}\right]_{\mathrm{K}}$ and Yankees $[\mathrm{j} æ j \mathrm{ki}: \mathrm{z}]_{\mathrm{E}} \rightarrow[\mathrm{jayk} \mathrm{hi}: \mathrm{si}]_{\mathrm{K}}(\mathrm{a}$ subscript $\mathrm{K}$ is attached to mark the Korean form; “ $\rightarrow$ " indicates the direction of adaptation). In contrast, the English non-morphemic /z/ undergoes a more variable adaptation. It is always borrowed as [c] when spelled with $\langle\mathrm{z}\rangle$, and borrowed as [s] or [s"] when spelled with $\langle\mathrm{s}\rangle$. These can be found in the adaptations of sizze [saIz $]_{\mathrm{E}} \rightarrow\left[\mathrm{s}^{*} \text { aicí }\right]_{\mathrm{K}}$ and pos $e\left[\mathrm{p}^{\mathrm{h}} \mathrm{O} \underline{\mathrm{z}}\right]_{\mathrm{E}} \rightarrow\left[\mathrm{p}^{\mathrm{h}} \mathrm{o}: \underline{\underline{s}}\right]_{\mathrm{K}}$. Apparently, the loanword shape is interfered with the spelling of English source words. Moreover, words from the SL may be adapted into the BL under different conditions, such as visual, auditory and mixed (visual + auditory) conditions. This gives rise to the interference of orthographic representations. As a consequence, random variations in the loanword adaptation often occur (Vendelin \& Peperkamp, 2006; Kang, 2009; Daland et al., 2015).

To summarize, the orthography should not be factored out in loanword studies as it implies the structures that borrowers focus on, such as grapheme-to-phoneme correspondence rules. It has a systematic impact on the borrowing results. Previous studies have demonstrated the orthography effect in French and Korean adaptations of English loanwords (Vendelin \& Peperkamp, 2006; Kang, 2009). However, there still lacks relevant studies on the adaptation of English loanwords into Mandarin which uses a logographic writing system and Pinyin to transcribe the sounds of Chinese characters using Roman alphabets

\subsection{Research questions}

The research questions in the current study revolve around the variable adaptation of English $[\mathrm{z}]_{\mathrm{E}}$ into Mandarin. The first question is related to the English $[\mathrm{z}]_{\mathrm{E}}$ and its mapping sounds in Mandarin, that is, 1) what are the possible corresponding sounds of English $[z]_{\mathrm{E}}$ when it is adapted into Mandarin? This question is the prerequisite as it matters to the different mapping strategies used by borrowers. Based on the answers to the first question, the second question is closely associated with the potential source that contributes to each adaptation strategy, namely, 2) is Mandarin adaptation of English $[z]_{E}$ significantly influenced by the source-loan spelling similarity? Once confirmed the 
significance of orthography effects, we are curious about how the factor of orthography interacts with the perceptual, phonological and structural factors, and determines the surface form of loanwords. Therefore, the third question is 3 ) how to formalize the impact of orthography in loanword adaptation by referring to Optimality Theory (OT)?

\section{Methods}

To address the research questions, we simultaneously conducted a corpus study and a perception experiment to examine the adaptation of English $[\mathrm{z}]_{\mathrm{E}}$ into Mandarin. The purpose was to find out the adaptation pattern. It is expected that the results from the corpus study and the perception experiment could corroborate each other.

\subsection{A loanword corpus study}

The loanwords under investigation were selected from Xin Hua Wai Lai Ci Ci Dian, a new Chinese loanword dictionary compiled by Shi (2019). To the best of our knowledge, this is by far one of the most updated, comprehensive and authoritative loanword dictionaries to study Chinese loanwords.

The English loanwords containing $[\mathrm{z}]_{\mathrm{E}}$ were classified according to its word position, such as initial, middle and ending positions. Their sounds and spellings were specially documented in preparation for further analysis. The Chi-square $(\chi 2)$ test was adopted to examine the association between two categorical variables, which were the sound-letter units of English source words (input) versus Mandarin loan words (output). The adaptation pattern will be directly identified from the test results.

\subsection{A perception experiment}

The perception experiment was designed to identify the Mandarin sounds that were perceptually similar to English $[\mathrm{z}]_{\mathrm{E}}$. The experiment was implemented in PsychoPy, a psycholinguistic software developed by (Peirce et al., 2019). Participants were ten Mandarin monolingual speakers, with their age ranging from 32 to 41 . They normally had extremely limited English learning experience. Stimuli were English non-words with CVC structure, with [z] distributed on the initial, middle and ending position of the non-words. The vowels were [æ], [i] and [u]. The consonants (except for $[\mathrm{z}]$ ) were stops, including $[\mathrm{p} / \mathrm{b}]_{\mathrm{E}},[\mathrm{t} / \mathrm{d}]_{\mathrm{E}}$ and $[\mathrm{k} / \mathrm{g}]_{\mathrm{E}}$. The full list of the stimuli was shown in Figure 1. An English native speaker (age $=28$ ) was invited to record the sounds of the listed stimuli in a sound attenuated room, using a TAKSTAR SM-16 microphone via Adobe Audition cc 2018 with a sampling rate of $44.1 \mathrm{kHz}$. Regarding the procedure, the experiment had three components, with one trial test and two real tests. Each component included three parts, with each corresponding to the position of $[\mathrm{z}]$ in the non-word stimuli (initial vs. middle vs. ending). Participants firstly received a trial test to familiarize the procedure. The stimuli within each part were randomly played. The detailed procedure was shown in Figure 1. After listening to the stimuli, participants were asked to identify and choose the fricative that they heard in the sounds of stimuli. Two options were given. One is $[\mathrm{ts}]_{\mathrm{M}}$, and the other is $[\mathrm{s}]_{\mathrm{M}}$, as well as other Mandarin fricatives and affricates that exclude $[\mathrm{ts}]_{\mathrm{M}}$. PsychoPy would automatically document participants' choices and reaction time (s). We also calculated the rates of $[\mathrm{ts}]_{\mathrm{M}}$ selection and the average reaction time for a single participant in each part.

The results were modeled by the one-way repeated measures ANOVA. The independent variables were Position, which means the position of $[\mathrm{z}]$ in the non-word. The dependent variables were either Rates (the [ts] selection rates) or RT (the average reaction time). The results could reveal the adaptation pattern from the perceptual account. 


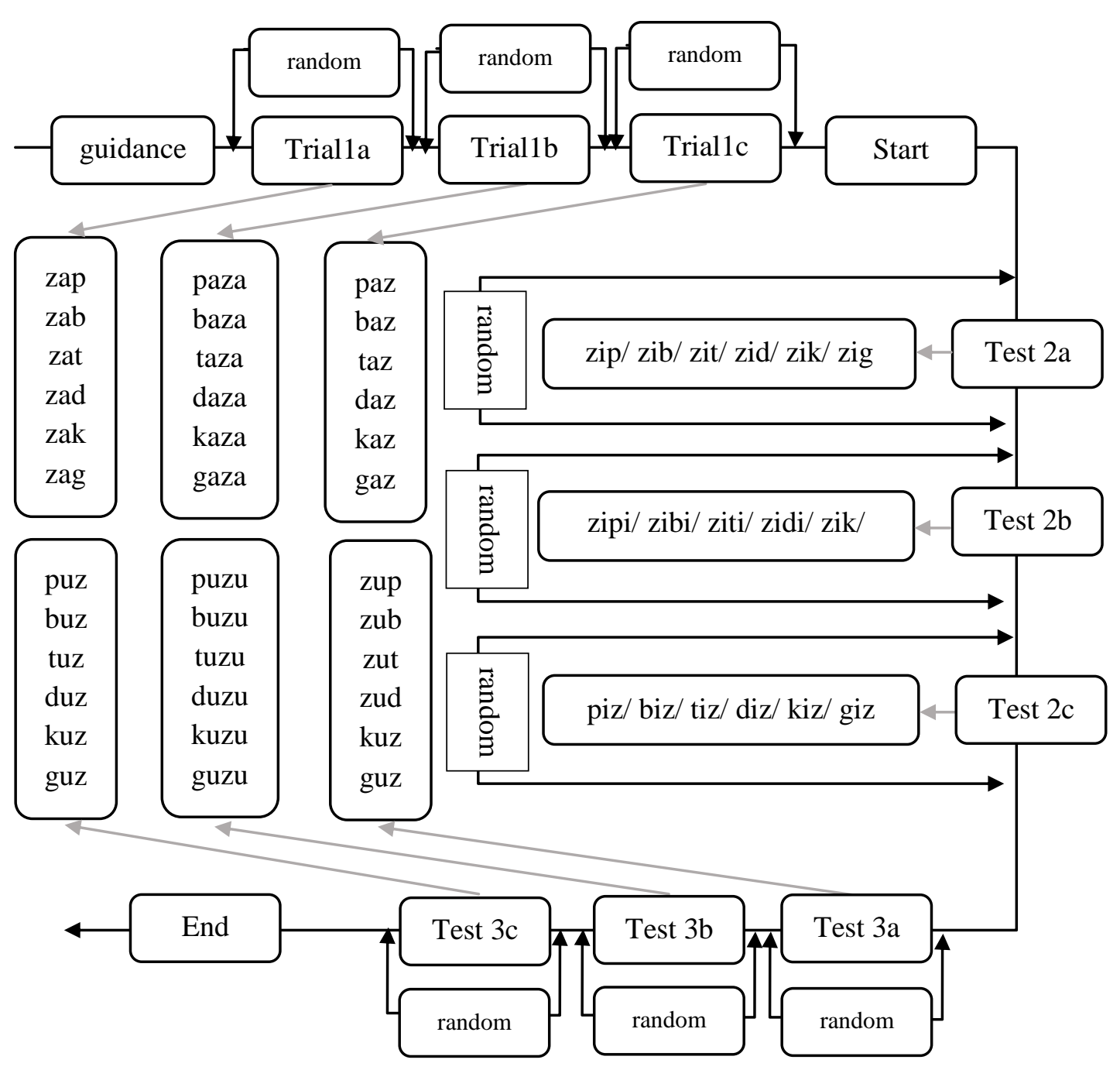

Figure 1. The procedure of $[\mathrm{z}]_{\mathrm{E}}$ perception experiment

\section{Results}

The results were divided into two parts. Section 3.1 introduced the results from the loanword corpus study. Section 3.2 presented the results from the perception experiment.

\subsection{Results from the corpus study}

As discussed in Section 1.1.1, the English $[\mathrm{z}]_{\mathrm{E}}$ is spelled with either $\langle\mathrm{s}\rangle$ or $\langle\mathrm{z}\rangle$, and its phonological distribution is flexible without restrictions. It can occupy the word initial, middle and ending position. Based on the letter-sound combination and the word position, we collected 140 English loanwords containing $[\mathrm{z}]_{\mathrm{E}}$. Some examples were given in (2) and (3). One noteworthy point was that the absence of $\langle\mathrm{s}\rangle[\mathrm{z}]_{\mathrm{E}}$ was due to the lack of relevant data as $\langle\mathrm{s}\rangle[\mathrm{z}]_{\mathrm{E}}$ rarely appeared on the word initial position. According to (2) and (3), the letter-sound units of $\langle\mathrm{s}\rangle[\mathrm{z}]_{\mathrm{E}}$ and $\langle\mathrm{z}\rangle[\mathrm{z}]_{\mathrm{E}}$ could correspond to various fricatives and affricates in Mandarin. As shown in Figure $2 \& 3$, the English letter-sound pair of $\langle\mathrm{s}\rangle[\mathrm{z}]_{\mathrm{E}}$, both in the word middle and ending position, was predominantly adapted into $\langle\mathrm{s}\rangle[\mathrm{s}]_{\mathrm{M}}$. Concerning the adaptation of $\langle\mathrm{z}\rangle[\mathrm{z}]_{\mathrm{E}}$, it was more likely to be borrowed as $\langle\mathrm{z}\rangle[\mathrm{ts}]_{\mathrm{M}}$. However, if the $\langle\mathrm{z}\rangle[\mathrm{z}]_{\mathrm{E}}$ occupied the word middle or ending position, the probability for $\langle\mathrm{z}\rangle[\mathrm{z}]_{\mathrm{E}}$ to be adapted into $\left\langle\mathrm{s}>[\mathrm{s}]_{\mathrm{M}}\right.$ increased, but not to a significant extent. The Chi-square $\left(\chi^{2}\right)$ test results 
confirmed the significant association between the input and the output, as demonstrated in the adaptation patterns of $\langle\mathrm{s}\rangle[\mathrm{z}]_{\mathrm{E}} \rightarrow\langle\mathrm{s}\rangle[\mathrm{s}]_{\mathrm{M}}$ and $\langle\mathrm{z}\rangle[\mathrm{z}]_{\mathrm{E}} \rightarrow\langle\mathrm{z}\rangle[\mathrm{ts}]_{\mathrm{M}}$ (see Table 3).

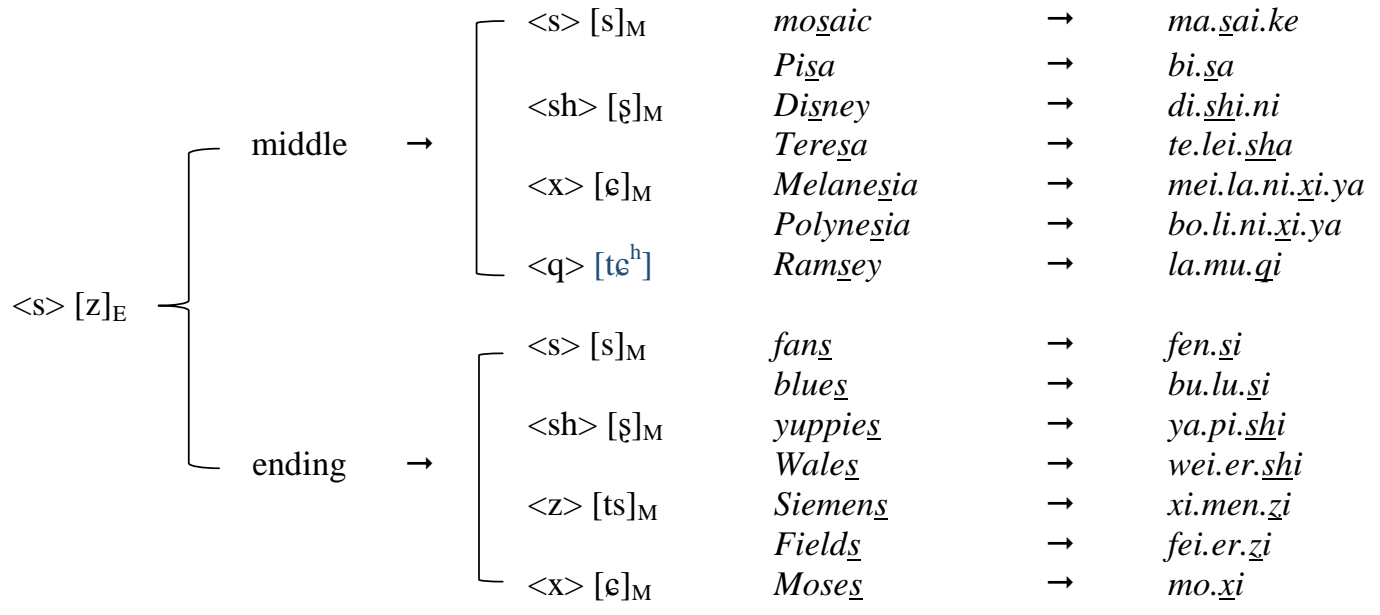

\begin{tabular}{|c|c|c|c|c|c|c|}
\hline & & & $\Gamma<\mathrm{z}>[\mathrm{ts}]_{\mathrm{M}}$ & Zorro & $\rightarrow$ & zииo.luo \\
\hline & & & & Zoloft & $\rightarrow$ & zиоo.luo. $f u$ \\
\hline & $\Gamma$ initial & $\rightarrow$ & $\langle\mathrm{zh}\rangle[\mathrm{ts}]_{\mathrm{M}}$ & Zeus & $\rightarrow$ & zhou.si \\
\hline & & & & $\underline{Z} \mathrm{ac}$ & $\rightarrow$ & zha.ke \\
\hline & & & $L\langle x\rangle[6]_{M}$ & $\underline{Z}$ etland & $\rightarrow$ & xi.de.lan \\
\hline & & & & $\underline{\text { Zealand }}$ & $\rightarrow$ & xi.lan \\
\hline & & & $\left\ulcorner\langle\mathrm{z}\rangle[\mathrm{ts}]_{\mathrm{M}}\right.$ & $U \underline{z} i$ & $\rightarrow$ & $w u . z i$ \\
\hline & & & & Lorenzo & $\rightarrow$ & lиo.lun.zиo \\
\hline & & & $\langle\mathrm{s}\rangle[\mathrm{s}]_{\mathrm{M}}$ & Arizona & $\rightarrow$ & ya.li.sang.na \\
\hline$\langle\mathrm{z}\rangle[\mathrm{z}]_{\mathrm{E}}$ & middle & $\rightarrow$ & & Tanzania & $\rightarrow$ & tan.sang.ni.ya \\
\hline & & & $\langle x\rangle[6]_{M}$ & Amāzon & $\rightarrow$ & ya.ma.xun \\
\hline & & & & Brażil & $\rightarrow$ & ba.xi $i$ \\
\hline & & & $L<\mathrm{zh}>[\mathrm{ts}]$ & Mozart & $\rightarrow$ & mo.zha.te \\
\hline & & & $\Gamma<\mathrm{z}\rangle[\mathrm{ts}]_{\mathrm{M}}$ & Lopez & $\rightarrow$ & luo.pei.zi \\
\hline & & & & Sanchez & $\rightarrow$ & sang.qie.zi $i$ \\
\hline & L ending & $\rightarrow$ & $\langle\mathrm{s}\rangle[\mathrm{s}]_{\mathrm{M}}$ & Lopez & $\rightarrow$ & lио.pei.si $\underline{i}$ \\
\hline & & & & Sanchez & $\rightarrow$ & sang.qie.si \\
\hline & & & $<\mathrm{sh}>[\mathrm{s}]_{\mathrm{M}}$ & $J a z \underline{z}$ & $\rightarrow$ & jue.shi \\
\hline
\end{tabular}

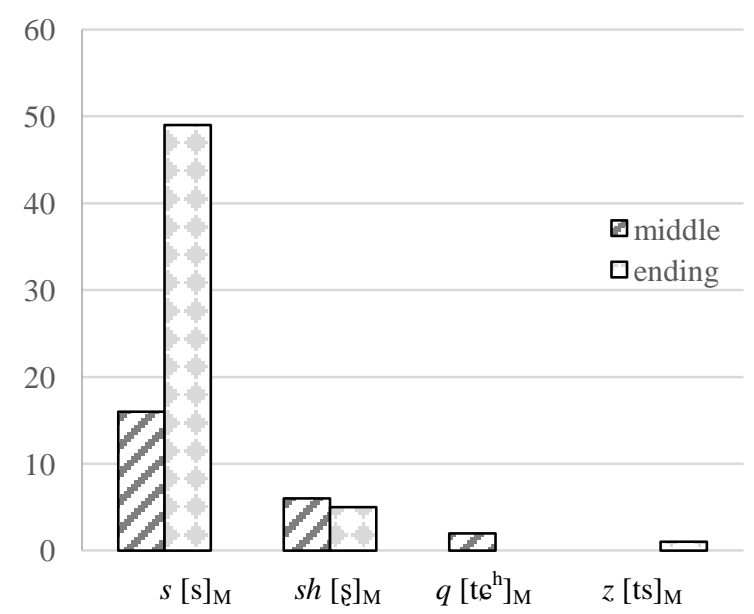

Figure 2. The adaptation of $\langle\mathrm{s}\rangle[\mathrm{z}]_{\mathrm{E}}$ 


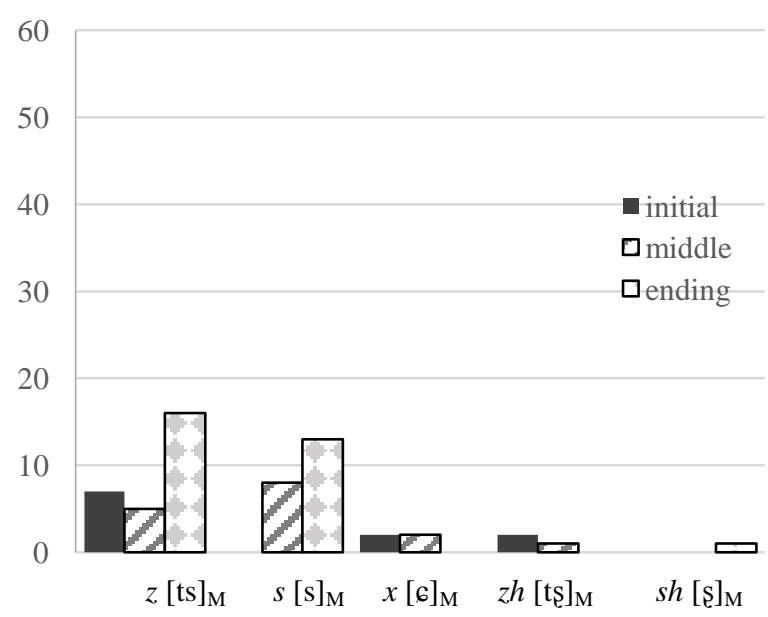

Figure 3. The adaptation of $\langle\mathrm{z}\rangle[\mathrm{z}]_{\mathrm{E}}$

Table 3. $C h i$-square $\left(\chi^{2}\right)$ test results

\begin{tabular}{|c|c|c|c|c|c|c|c|c|c|}
\hline & & $z[\mathrm{ts}]_{\mathrm{M}}$ & $s[\mathrm{~s}]_{\mathrm{M}}$ & $\operatorname{sh}[\mathrm{s}]_{\mathrm{M}}$ & $x[6]_{\mathrm{M}}$ & $q\left[\mathrm{t}^{\mathrm{h}}\right]_{\mathrm{M}}$ & $z h\left[\mathrm{ts}_{\mathrm{S}}\right]_{\mathrm{M}}$ & total & proportion \\
\hline \multirow[t]{4}{*}{ Observation } & $s[\mathrm{z}]_{\mathrm{E}}$ & 1 & 65 & 11 & 4 & 2 & 0 & 83 & $59.3 \%$ \\
\hline & $z[\mathrm{z}]_{\mathrm{E}}$ & 28 & 21 & 1 & 4 & 0 & 3 & 57 & $40.7 \%$ \\
\hline & total & 29 & 86 & 12 & 8 & 2 & 3 & 140 & \\
\hline & proportion & $20.7 \%$ & $61.5 \%$ & $8.5 \%$ & $5.7 \%$ & $1.4 \%$ & $2.2 \%$ & & $100 \%$ \\
\hline \multirow[t]{4}{*}{ Expected } & $s[\mathrm{z}]_{\mathrm{E}}$ & 17.18 & 51.00 & 7.06 & 4.73 & 1.16 & 1.83 & 83 & \\
\hline & $z[\mathrm{z}]_{\mathrm{E}}$ & 11.82 & 35.00 & 4.94 & 3.27 & 0.84 & 1.17 & 57 & \\
\hline & total & 29 & 86 & 12 & 8 & 2 & 3 & 140 & \\
\hline & proportion & $20.7 \%$ & $61.5 \%$ & $8.5 \%$ & $5.7 \%$ & $1.4 \%$ & $2.2 \%$ & & $100 \%$ \\
\hline \multirow[t]{2}{*}{$(o-e)^{2} / e$} & $s[\mathrm{z}]_{\mathrm{E}}$ & 15.24 & 3.84 & 2.20 & 0.11 & 0.76 & 1.83 & \multirow{2}{*}{\multicolumn{2}{|c|}{$\begin{array}{c}\chi^{2}=58.73>16.81 \\
d f=6 ; p<0.01^{* *}\end{array}$}} \\
\hline & $z[\mathrm{z}]_{\mathrm{E}}$ & 22.15 & 5.60 & 3.14 & 0.16 & 0.84 & 2.86 & & \\
\hline
\end{tabular}

\subsection{Results from the perception experiment}

With regarding to the $[t s]_{M}$ selection rates, when the sound of $[\mathrm{z}]_{\mathrm{E}}$ was in the initial and middle position, participants tended to perceive it as $[\mathrm{ts}]_{\mathrm{M}}$, rather than other Mandarin fricatives and affricates. However, when $[\mathrm{z}]_{\mathrm{E}}$ was in the ending position, the $[\mathrm{ts}]_{\mathrm{M}}$ selection rates were similar to the rates of non- $[\mathrm{ts}]_{\mathrm{M}}$ selection, as shown in Table 4 and Figure 4. Concerning the reaction time, participants tended to spend more time identifying the sound of $[\mathrm{z}]_{\mathrm{E}}$ as $[\mathrm{ts}]_{\mathrm{M}}$ when it was placed in the word ending position. In contrast, they would spend less time perceiving the $[\mathrm{z}]_{\mathrm{E}}$ sound when it occupied the word initial and middle position, as shown in Table 5 and Figure 5. The one-way-repeated measures ANOVA test confirmed the significant impact of $[\mathrm{z}]_{\mathrm{E}}$ position in the source word on the $[\mathrm{ts}]_{\mathrm{M}}$ selection rates $([F(1,3)=21.40, p<0.001])$ and reaction time $([F(1,3)=16.45, p<0.001])$.

Table 4. The descriptive data regarding the $[\mathrm{ts}]_{\mathrm{M}}$ selection rates

\begin{tabular}{cccccc}
\hline$[\mathrm{ts}]_{\mathrm{M}}$ selection rates & Min. & Max. & Median & Mean $(\mu)$ & Std. \\
\hline initial & 0.00 & 1.00 & 0.50 & 0.89 & 0.38 \\
middle & 0.08 & 0.92 & 0.50 & 0.75 & 0.27 \\
ending & 0.17 & 0.83 & 0.50 & 0.58 & 0.14 \\
\hline
\end{tabular}


Table 5. The descriptive data regarding the reaction time (s)

\begin{tabular}{cccccc}
\hline reaction time (s) & Min. & Max. & Median & Mean $(\mu)$ & Std. \\
\hline initial & 1.25 & 5.87 & 2.77 & 2.96 & 1.07 \\
middle & 1.79 & 7.54 & 3.30 & 3.75 & 1.35 \\
ending & 2.41 & 8.05 & 4.52 & 4.75 & 1.49 \\
\hline
\end{tabular}

Generally speaking, when $[\mathrm{z}]_{\mathrm{E}}$ was at the beginning of a word, Mandarin native speakers could perceive the $[\mathrm{z}]_{\mathrm{E}}$ sound as $[\mathrm{ts}]_{\mathrm{M}}$ much more accurately and quickly. On the contrary, when $[\mathrm{z}]_{\mathrm{E}}$ was in the middle or at the end, the probability that Mandarin monolingual speakers identify $[\mathrm{z}]_{\mathrm{E}}$ sound as other fricatives or affricates greatly increased, and their reaction time also increased. These indicated that their uncertainty in perceiving the $[\mathrm{z}]_{\mathrm{E}}$ sound improved significantly. From perceptual and acoustic account, the [sonority] of fricatives originates from the turbulent noise. When the turbulent noise is generated, the vocal organs form a narrow gap at the contraction point in the acoustic cavity. The nasopharyngeal passage is closed, and the pressure in the acoustic cavity significantly increased. The pressure difference between the upper and lower glottis is reduced. As a consequence, the intensity of the vibration of the vocal cords becomes weakened or stops. If the slit formed at the contraction point is not completely closed, the [+continuant] noise, that is, the turbulence noise, will generate. When the fricative is in the middle or at the end of a word, the [continuant] of the turbulent noise becomes weakened, and the energy value and intensity also reduced. As a result, the perceptual salient fricative $[\mathrm{z}]_{\mathrm{E}}$ with [+sonority] and [+continuant] is very likely to be perceived as weak affricates with [-sonority] and [-continuant] (Stevens \& Keyser, 1989; Keyser \& Stevens, 2006).

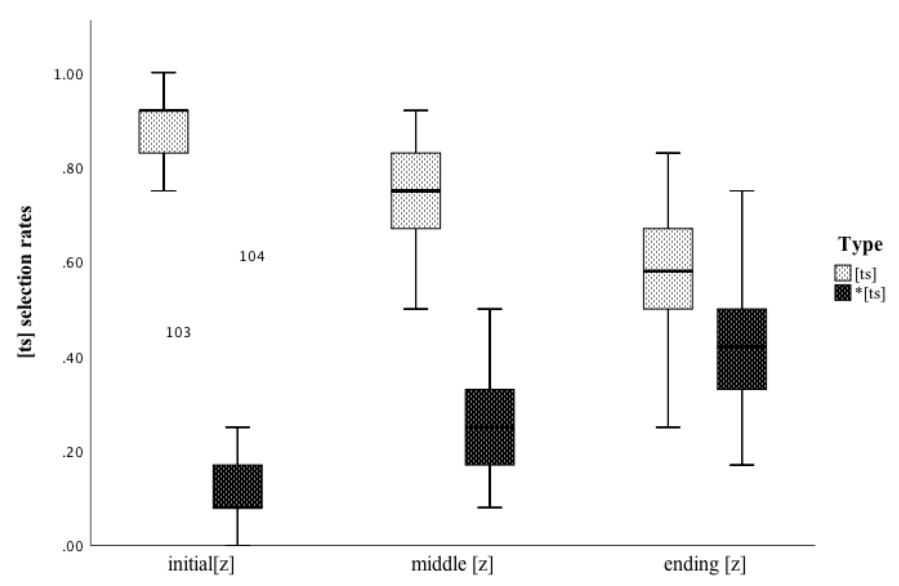

Figure 4. The $[\mathrm{ts}]_{\mathrm{M}}$ selection rates according to positions

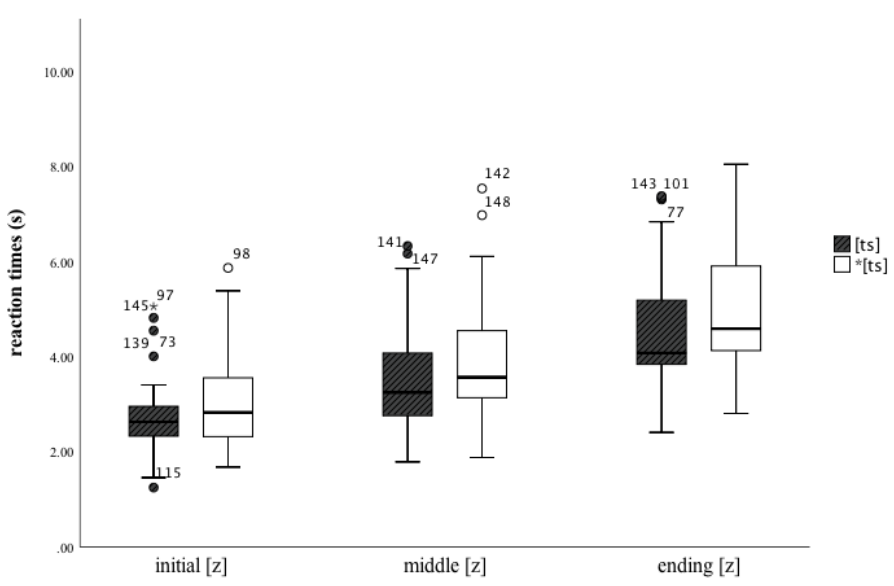

Figure 5. The reaction time (s) according to positions 


\section{Discussion}

Two major adaptation patterns are identified when borrowing the English $[\mathrm{z}]_{\mathrm{E}}$ into Mandarin, that is, $\langle\mathrm{s}\rangle[\mathrm{z}]_{\mathrm{E}} \rightarrow\langle\mathrm{s}\rangle[\mathrm{s}]_{\mathrm{M}}$ and $\langle\mathrm{z}\rangle[\mathrm{z}]_{\mathrm{E}} \rightarrow\langle\mathrm{z}\rangle[\mathrm{ts}]_{\mathrm{M}}$. The former is mainly based on the source-loan spelling similarity, while the later predominantly conforms to the perceptual similarity. The results will be interpreted within the framework of Optimality Theory (OT). We will put forward the relevant perceptual, phonological, structural and orthographic constraints, and their interactions during the lexical borrowing process.

\subsection{Perceptual, phonological, structural and orthographic constraints}

The perception-based and phonology-based constraints require a perceptual and phonological mapping between source words and loan words. Previous studies on loanwords have reached a consensus that the sounds of source words and loan words should be as similar as possible (Silverman, 1992; Miao, 2005; Yip, 2006; Kenstowicz, 2007; Hsieh et al., 2008; Lin, 2008; Peperkamp et al., 2008; Kang, 2009; Hsieh, 2014). Based on the findings in Section 3.1 and 3.2, the English sound of $[\mathrm{z}]_{\mathrm{E}}$ is perceptually similar to $[\mathrm{ts}]_{\mathrm{M}}$ in Mandarin. When $[\mathrm{z}]_{\mathrm{E}}$ is located at the beginning of the loanword, Mandarin monolingual speakers tend to choose $[\mathrm{ts}]_{\mathrm{M}}$ to match it. When $[\mathrm{z}]_{\mathrm{E}}$ is in the middle position of the loanword, the sound [ts] $]_{M}$ provides a better overall match in phonetic details, in comparison to $[\mathrm{s}]_{\mathrm{M}}$. When $[\mathrm{z}]_{\mathrm{E}}$ occupies the ending position of the loanword, the adaptation patterns will be more variable as it may correspond to $[\mathrm{ts}]_{\mathrm{M}},[\mathrm{s}]_{\mathrm{M}},[\mathrm{ts}]_{\mathrm{M}}$ or $[\mathrm{s}]_{\mathrm{M}}$. In this sense, it is difficult to identify a predominant adaptation pattern when $[\mathrm{z}]_{\mathrm{E}}$ is in the ending position. This paper proposes the following constraints related to the perceptual and phonological similarity, as shown in (4) (all constraints proposed in this paper are only applied to the fricatives and related syllables in the input and output forms; the violation marks are assigned to unfaithful mapping with respect to fricatives and affricates. If other segments and syllables in the surface form of the loanword violate the following constraints, the number of violation markers will not be superimposed temporarily. The purpose was to highlight and focus on the adaptation of fricatives and affricates). They are all faithfulness constraints which aim to maintain the perceptual salience and phonological features, while prevents sound alternations during the adaptation. MIMIC constraints are different from IDENT constraints as they only require the perceptual similarity, but not the absolute identical mapping between the input and the output segments.

(3) Perception-based and phonology-based constraints in the adaptation of [z $]_{\mathrm{E}}$ into Mandarin

MIMIC-CONSONANT: the input and the output consonants must be perceptually similar;

MIMIC-VOWEL: the input and the output vowels must be perceptually similar;

IDENT-[anterior]: the input and the output fricatives and affricates must be faithful in their [anterior] feature;

IDENT-[aspiration]: the input and the output fricatives and affricates must be faithful in their [aspiration] feature;

DEP-IO: the insertion is forbidden in the mapping from the input to the output;

The structural constraints put restrictions on the output structures. Non-existent segments and illicit structures in the borrowing language are forbidden. In the present study, the structural constraints are related to the Mandarin phonotactics regarding fricatives and affricates, as listed in (4). The setting of AGREE-BACK guarantees the phonological assimilation in the combination of alveolar / retroflex fricatives / affricates $\left([\mathrm{ts}]_{\mathrm{M}},\left[\mathrm{ts}^{\mathrm{h}}\right]_{\mathrm{M}},[\mathrm{s}]_{\mathrm{M}}\right.$ vs. $\left.[\mathrm{ts}]_{\mathrm{M}},\left[\mathrm{ts}^{\mathrm{h}}\right]_{\mathrm{M}},[\mathrm{s}]_{\mathrm{M}}\right)$ and apical vowels $\left([\mathrm{I}]_{\mathrm{M}}\right.$ vs. $\left.[\tau]_{\mathrm{M}}\right)$. The 
alveolar fricatives / affricates co-occur with the apical front vowel of $[\mathrm{I}]_{\mathrm{M}}$, while the retroflex fricatives / affricates are combined with the apical back vowel $[\tau]_{\mathrm{M}}$. The fricatives / affricates and the apical vowels should agree in their place of articulation. In this respect, the sequence of [ts. $]_{M}$ is licit, while the sequence of " $[\mathrm{ts} .]_{\mathrm{M}}$ is illicit and violates the constraint of AGREE-BACK (Cheng, 1973; Pulleyblank, 1983; Lin, 1989). Moreover, the constraint of *ALVEOLAR-IN represents another Mandarin phonotactics, which forbids the combination of alveolar fricatives and the sequences of [in]. Due to this constraint, the co-occurrences of ${ }^{*}[\operatorname{tsin}]_{\mathrm{M}},{ }^{*}\left[\mathrm{ts}^{\mathrm{h}} \mathrm{in}\right]_{\mathrm{M}}$, and ${ }^{*}[\sin ]_{\mathrm{M}}$ are illicit (Lee \& Zee, 2003; Mou, 2006; Duanmu, 2007; Lin, 2007).

(4) Structural constraints in the adaptation of $[\mathrm{z}]_{\mathrm{E}}$ into Mandarin

AGREE-BACK: the phonemes in the same domain must agree in their backness feature;

*ALVEOLAR-IN: the alveolar fricatives must not be adjacent to the sequences of [in];

When reading the source word, its pronunciation is mapped to the perceptually similar sound in the borrowing language, thus forming a BL grapheme-to-phoneme pair. The borrowers also use this sound-letter pair to retrieve the appropriate form-meaning pair from their mental vocabulary. For the mapping process from the source word spelling to the loan word pronunciation, Hamman \& Colombo (2017) proposed three general constraints related to the motivation of orthography, as shown in (5). According to the general orthography-based adaptations, this paper proposed the specific orthographybased constraints in the adaptation of $[\mathrm{z}]_{\mathrm{E}}$ into Mandarin. The function of $\langle\mathrm{z}\rangle_{\mathrm{E}}[\mathrm{ts}]_{\mathrm{M}}$ and $\langle\mathrm{s}\rangle_{\mathrm{E}}[\mathrm{s}]_{\mathrm{M}}$ is to exclude the candidates that are not affected by spelling. In the previous studies on Chinese loanwords, we found that Mandarin native speakers living in mainland China would refer to the written form and tend to retain all the segments of the borrowing language, such as Friedman [f.ii:dmən] $]_{\mathrm{E}} \rightarrow$ fu.li.de.man [fu.li.tr.man $]_{\mathrm{M}}$ (Yip, 2006; Hsieh, 2014). In contrast, Mandarin native speakers in Taiwan will delete segments that are not perceptually salient. For example, the same word Friedman [f.ii:dmən $]_{\mathrm{E}}$ is adapted into Mandarin as fu.li.man [fu.li.man $]_{\mathrm{M}}$. The stop [d] in the source word Friedman was deleted in the adaptation because stops are not salient in perception. The sonority of the sound is related to the opening and closing of the vocal cavity. The active and passive vocal organs are close when the stop sound is pronounced. Consequently, the airflow path is completely blocked. Therefore, the stop has the lowest sonority level (Miao, 2005; Mou, 2006; Zsiga, 2013).

(5) General orthography-based constraints (Hamman \& Colombo, 2017)

$\leq \beta>[\mathrm{P}]$ : every spelling form $\langle\beta\rangle$ in the source word must correspond to a sound in the loan word;

$*<\beta>$ []: assign a violation mark to every $\langle\beta>$ in the source word without a correspondence to a sound in the loan word;

$*<>[\mathrm{P}]$ : assign a violation mark to every $[\mathrm{p}]$ in the loan word without a correspondence to a spelling form in the source word;

(6) Specific orthography-based constraints in the adaptation of $[\mathrm{z}]_{\mathrm{E}}$ into Mandarin

$\langle\mathrm{Z}\rangle_{\underline{E}}[t s]_{\underline{M}}$ : every $\langle\mathrm{z}\rangle_{\mathrm{E}}$ in the source word must correspond to a $[\mathrm{ts}]_{\mathrm{M}}$ sound in the loan word;

$\langle\mathrm{S}\rangle_{\mathrm{E}}[\mathrm{S}]_{\mathrm{M}}$ : every $\langle\mathrm{S}\rangle_{\mathrm{E}}$ in the source word must correspond to a $[\mathrm{s}]_{\mathrm{M}}$ sound in the loan word;

$\left.{ }^{*}\langle\mathrm{Z}\rangle_{\mathrm{E}} \perp\right]_{\mathrm{M}}$ : assign a violation mark to every $\langle\mathrm{z}\rangle_{\mathrm{E}}$ in the source word without a correspondence to a sound in the Mandarin loan word;

$\left.\underline{* \mathrm{~S}}\rangle_{\mathrm{E}}\right]_{\mathrm{M}}$ : assign a violation mark to every $\langle\mathrm{s}\rangle_{\mathrm{E}}$ in the source word without a correspondence 
to a sound in the Mandarin loan word;

To summarise, this paper puts forward various constraints based on speech perception, phonology, structures and orthography. These constraints are divided into two types, faithfulness and markedness constraints. Generally speaking, the perception-based, the phonology-based and the orthography-based adaptations belong to faithfulness constraints, which prevents sound change. In contrast, the structural constraints are markedness constraints, which force to sound change. Their interactions determine the surface form of the loanword in actual use. The next section will discuss how these constraints interact with each other.

\subsection{OT analysis of Mandarin adaptation of English $[z]_{E}$}

The adaptation of $[\mathrm{z}]_{\mathrm{E}}$ words involves the constraints related to the phonology, phonetics, structure, and orthography. This paper provides a formal analysis and explanation of their interactions within the framework of OT. When the same spelling form corresponds to different sounds in the SL and BL, the orthography-based constraints outrank the other constraints. A case in point is the adaptation pattern of $\langle\mathrm{s}\rangle[\mathrm{z}]_{\mathrm{E}} \rightarrow\langle\mathrm{s}\rangle[\mathrm{s}]_{\mathrm{M}}$, which can be understood as an orthography-based adaptation. When the same spelling form is matched to perceptually similar sounds in the SL and BL, the ranking of different types of constraints will be flexible, without specific restrictions. In this sense, the function of each type of constraint is not differentiated. A typical example is the correspondence of $\langle\mathrm{s}\rangle[\mathrm{z}]_{\mathrm{E}} \rightarrow\langle\mathrm{z}\rangle$ $[\mathrm{ts}]_{\mathrm{M}}$, which can be characterized as a mixed adaptation pattern influenced by the phonology, phonetics, structures and orthography together. We take the adaptation of mosaic and Zambia as examples to illustrate the above adaptation patterns. The OT tableaus are listed in Table 6 and Table 7 , respectively.

Table 6. The adaptation of mosaic

\begin{tabular}{|c||c|c|c|c|}
\hline$<\mathrm{sai}>[\mathrm{zeI}]_{\mathrm{E}}$ & $\langle\mathrm{s}\rangle_{\mathrm{E}}[\mathrm{s}]_{\mathrm{M}}$ & $\langle\mathrm{s}\rangle_{\mathrm{E}}[]_{\mathrm{M}}$ & IDENT-[anterior] & MIMIC-CONSONANT \\
\hline \hline$<<\mathrm{sai}>[\mathrm{saI}]_{\mathrm{M}}$ & & & & $*$ \\
\hline$<\mathrm{zai}>[\mathrm{tsaI}]_{\mathrm{M}}$ & $* !$ & & & $*$ \\
\hline$<\mathrm{ai}>[\mathrm{aI}]_{\mathrm{M}}$ & $* !$ & $* !$ & $*$ & $*$ \\
\hline <shai $>[\mathrm{saI}]_{\mathrm{M}}$ & $* !$ & & $*$ & $*$ \\
\hline$<$ zhai $>[\mathrm{tsaI}]_{\mathrm{M}}$ & $* !$ & & $*$ & $*$ \\
\hline
\end{tabular}

Table 7. The adaptation of Zambia

\begin{tabular}{|c||c|c|c|c|}
\hline$<\mathrm{zam}>[\mathrm{zam}]_{\mathrm{E}}$ & $\langle\mathrm{z}\rangle_{\mathrm{E}}[\mathrm{ts}]_{\mathrm{M}}$ & $\langle\mathrm{z}\rangle_{\mathrm{E}}[]_{\mathrm{M}}$ & IDENT-[anterior] & MIMIC-CONSONANT \\
\hline \hline$<\mathrm{zan}>[\mathrm{tsan}]_{\mathrm{M}}$ & & & & \\
\hline$<\mathrm{san}>[\mathbf{s a n}]_{\mathrm{M}}$ & $*$ & & $*$ & $*$ \\
\hline$<\mathrm{an}>[\mathrm{an}]_{\mathrm{M}}$ & $*$ & $*$ & $*$ & $*$ \\
\hline$<\operatorname{shan}>[\mathbf{s a n}]_{\mathrm{M}}$ & $*$ & & $*$ & $*$ \\
\hline$<$ zhan $>[\text { tsan }]_{\mathrm{M}}$ & $*$ & & $*$ & $*$ \\
\hline
\end{tabular}

The OT tableaus as presented in Table 6 and Table 7 adopts the same set of constraints. The difference is that the orthography-based constraints in Table 6 dominate (rank higher than) the perceptual and phonological constraints, as marked by the solid line. In Table 7, the ranking of all constraints is not restricted, as marked by the dotted line. In Table 6, the orthography-based constraints of $\langle\mathrm{s}\rangle_{\mathrm{E}}[\mathrm{s}]_{\mathrm{M}}$ and $\langle\mathrm{s}\rangle_{\mathrm{E}}[]_{\mathrm{M}}$ rank higher than the perceptual constraint of MIMIC-CONSONANT. This ranking order can exclude the candidates whose input and output spellings are not identical. As a result, the candidates of $<$ zai $>[\mathrm{tsaI}]_{\mathrm{M}},<$ shai $>[\mathrm{saI}]_{\mathrm{M}}$ and $<$ zhai $>[\text { tsaI }]_{\mathrm{M}}$ are excluded at first. One noteworthy point is that the winner <sai> $[\mathrm{saI}]_{\mathrm{M}}$ and the loser $<$ zai $>[\mathrm{tsaI}]_{\mathrm{M}}$ have the same number of 
violation markers. However, the winner does better than the loser, as it only violates a lower-ranked perception-based constraint, MIMIC-CONSONANT. In comparison, the loser violates a higher-ranked orthography-based adaptation, thus leading to a vital violation. Therefore, in an adaptation heavily influenced by the source-loan spelling similarity, the orthography-based constraints rank higher than those based on perceptual and phonological similarity.

The constraint set in Table 7 does not have a fixed ranking. The candidate <zan> [tsan $]_{M}$ not only satisfies the orthography-based adaptations, but also conforms to the requirements of phonetic, phonological and structural constraints. As the <zan> $[\operatorname{tsan}]_{M}$ violates the constraints to the least extent, it is denoted as the final winner output. In comparison, the other rivals more or less violate one or more constraints, thus being denoted as the loser outputs.

Generally, we can use the same ranking order of constraints to select the optimal output, that is, $<\beta>[\mathrm{P}], *<\beta>[]>>$ IDENT-[anterior], MIMIC-CONSONANT. However, this ranking order ignores the BL phonotactics. The fact is that if possible, the structural constraints also have an impact on the output surface form. For example, the sequences of [ki] is licit in English, but illicit in Mandarin. According to Mandarin phonotactics, the velar stops $[\mathrm{k}]$ or $\left[\mathrm{k}^{\mathrm{h}}\right]$ cannot co-occur with the high front vowel [i]. When adapting the English containing the sequences of $[\mathrm{ki}]_{\mathrm{E}}$ or $\left[\mathrm{k}^{\mathrm{h}} \mathrm{i}\right]_{\mathrm{E}}$, the velar stop $[\mathrm{k}]_{\mathrm{E}}$ or $\left[\mathrm{k}^{\mathrm{h}}\right]_{\mathrm{E}}$ will undergo palatalization into $\left[\mathrm{tc}^{\mathrm{h}}\right]_{\mathrm{M}}$. The English word Kissinger $\left[\mathrm{k}^{\mathrm{h}} \mathrm{Isnd}{ }{ }^{2}\right]_{\mathrm{E}}$ is borrowed as ji.xin.ge $\left[\mathrm{t}^{\mathrm{h}} \mathrm{i} . \operatorname{cin} . \mathrm{kr}\right]_{\mathrm{M}}$. This constraint is formalized as *VELAR-I (Ma, 2008). Similarly, the adaptation of $[\mathrm{z}]_{\mathrm{E}}$ also confront with many phonotactic restrictions, and needs to take the structural constraints into consideration. To demonstrate and illustrate the role of structural constraints, we used the adaptation of $U z i[\mathrm{u}: \underline{z i}]_{\mathrm{E}}$ and Lisbon $[\mathrm{l} \underline{\mathrm{z}} \underline{b} \mathrm{bn}]_{\mathrm{E}}$ as an example, the relevant $\mathrm{OT}$ analyses were presented in Table 8 and Table 9.

Table 8. The adaptation of $U z i$

\begin{tabular}{|c||c|c|c|}
\hline$<\mathrm{zi}>[\mathrm{zi}]_{\mathrm{E}}$ & AGREE-BACK & $\langle\mathrm{z}\rangle_{\mathrm{E}}[\mathrm{ts}]_{\mathrm{M}}$ & MIMIC-VOWEL \\
\hline \hline$<\mathrm{zi}>[\mathrm{tsI}]_{\mathrm{M}}$ & & & $*$ \\
\hline$<\mathrm{si}>[\mathrm{su}]_{\mathrm{M}}$ & & $* !$ & $*$ \\
\hline$<\mathrm{zhi}>[\mathrm{ts} \cdot \mathrm{c}]_{\mathrm{M}}$ & & $* !$ & $*$ \\
\hline$<\mathrm{shi}>[\mathrm{s} . \mathrm{J}]_{\mathrm{M}}$ & & & \\
\hline$<\mathrm{zi}>[\mathrm{tsi}]_{\mathrm{M}}$ & $* !$ & $* !$ & \\
\hline$<\mathrm{si}>[\mathrm{si}]_{\mathrm{M}}$ & $* !$ & $* !$ & \\
\hline$<\mathrm{zhi}>[\mathrm{tsi}]_{\mathrm{M}}$ & $* !$ & $* !$ & \\
\hline$<\mathrm{shi}>[\mathrm{si}]_{\mathrm{M}}$ & & $* !$ & \\
\hline$<\mathrm{xi}>[\mathrm{ci}]_{\mathrm{M}}$ & $* !$ & $* !$ & \\
\hline$<\mathrm{ji}>[\mathrm{tsi}]_{\mathrm{M}}$ & $* !$ & &
\end{tabular}

Table 9. The adaptation of Lisbon

\begin{tabular}{|c||c|c|c|}
\hline$<\mathrm{s}>[\mathrm{z}]_{\mathrm{E}}$ & AGREE-BACK & $\langle\mathrm{s}\rangle_{\mathrm{E}}[\mathrm{s}]_{\mathrm{M}}$ & DEP-IO \\
\hline \hline$<\mathrm{si}>[\mathrm{s.}]_{\mathrm{M}}$ & & & $*$ \\
\hline$<\mathrm{zi}>[\mathrm{ts} .]_{\mathrm{M}}$ & & $*$ & $*$ \\
\hline$<\mathrm{shi}>[\mathrm{s} .]_{\mathrm{M}}$ & & $*$ & $*$ \\
\hline$<\mathrm{zhi}>[\mathrm{s} .]_{\mathrm{M}}$ & & $*$ & $*$ \\
\hline$<\mathrm{si}>[\mathrm{si}]_{\mathrm{M}}$ & $* !$ & & $*$ \\
\hline$<\mathrm{zi}>[\mathrm{si}]_{\mathrm{M}}$ & $* !$ & $*$ & $*$ \\
\hline$<\mathrm{shi}>[\mathrm{si}]_{\mathrm{M}}$ & $* !$ & $*$ & $*$ \\
\hline$<\mathrm{zhi}>[\mathrm{si}]_{\mathrm{M}}$ & $* !$ & $*$ & $*$ \\
\hline
\end{tabular}


The structural constraint AGREE-BACK applies to avoid alveolar / retroflex fricatives and affricates to co-occur with the high front vowel. In this respect, the candidates containing the illicit sound structures of $*<\mathrm{zi}>[\mathrm{tsi}]_{\mathrm{M}}, *<\mathrm{si}>[\mathrm{si}]_{\mathrm{M}}, *<\mathrm{zhi}>[\mathrm{tsi}]_{\mathrm{M}}$ and $*<\mathrm{shi}>[\mathrm{si}]_{\mathrm{M}}$ will be ruled out in the selection of the optimal output. Even though they have licit written forms, the high front vowel does not undergo the phonological assimilation influenced by the preceding fricatives and affricates. The licit

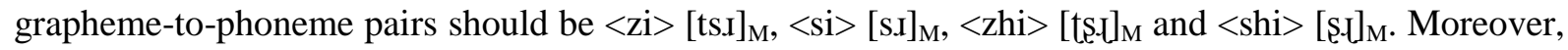
the ranking of the structural constraint AGREE-BACK and the orthography-based constraints is not fixed, as marked by the dotted line. The OT analysis presume the richness of the base, which means that there are no language-specific restrictions on the input. To prioritize the ranking of the structural constraint can rule out the candidates with illicit sound structures according to the BL phonological restrictions. The higher ranking of the orthography-based constraint can guarantee the spelling similarity between the input and the output. The candidates whose written forms are different from the input will be denoted as the loser in the evaluation. In this sense, the structural constraint does not conflict with the orthographic constraint as they both function to predict and select the optimal candidate. In contrast, as the optimal output deviates from the perceptual similarity and sound structures with the input, the ranking of the perceptual and phonological constraints should be lower in order to make the outputs of $\langle\mathrm{zi}\rangle[\mathrm{tsI}]_{\mathrm{M}}$ and $\langle\mathrm{si}\rangle[\mathrm{sI}]_{\mathrm{M}}$ become the winners in the competition.

In summary, the above OT analyses suggest that the structural constraints always rank higher than the orthography-based constraints during the adaptation. When borrowers are uncertain or unknown about the phonemic identity of the source word, the orthography effect will be maximized in the lexical borrowing. At this time, the ranking of the orthography related constraints is higher than the perceptual and phonological constraints. Such adaptation is dominated by the source-loan spelling similarity. The interactions and ranking of different constraints are illustrated in Figure 6.

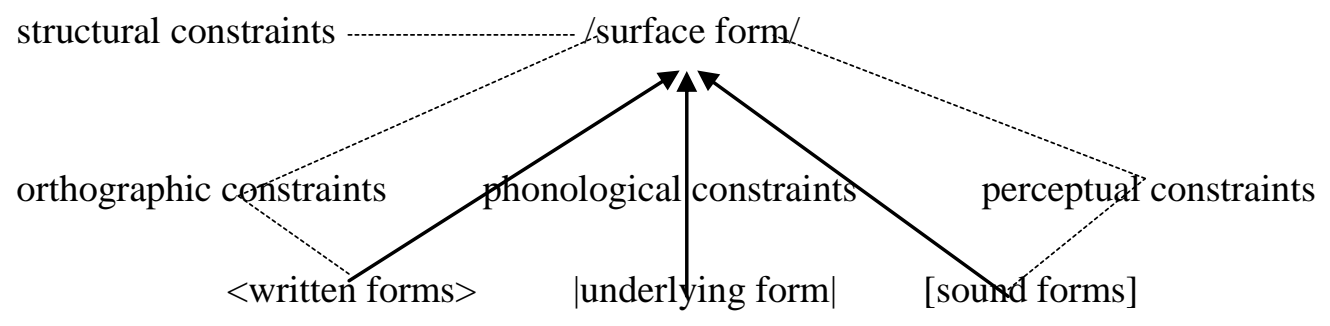

Figure 6. The interaction and ranking of different constraints

\section{Conclusion}

This paper explores the adaptation of English alveolar fricative $[z]_{\mathrm{E}}$ into Mandarin, thereby discussing the role of orthography in the lexical borrowing. The main findings are as follows: 1) the sound of $[\mathrm{z}]_{\mathrm{E}}$ is perceptually similar to Mandarin $[\mathrm{ts}]_{\mathrm{M}}$ and $\left.[\mathrm{s}]_{\mathrm{M}} ; 2\right)$ from perceptual account, when $[\mathrm{z}]_{\mathrm{E}}$ is located at the beginning or in the middle of an English source word, Mandarin monolingual speakers tend to perceive $[\mathrm{z}]_{\mathrm{E}}$ as $[\mathrm{ts}]_{\mathrm{M}}$. However, when $[\mathrm{z}]_{\mathrm{E}}$ occupies the ending position of the word, it may be matched by $[\mathrm{ts}]_{\mathrm{M}},[\mathrm{s}]_{\mathrm{M}},[\mathrm{ts}]_{\mathrm{M}}$ or $[\mathrm{s}]_{\mathrm{M}}$. The correspondence becomes more variable. This also suggests that the application of the perceptual constraint MIMIC-CONSONANT depends on the position of $[\mathrm{z}]_{\mathrm{E}}$ in the source word; 3 ) if one written form corresponds to a completely different sounds in the SL and BL, and borrowers are uncertain or unknown about the accurate pronunciation of the source word, the orthography effect is maximal in determining the shape of loanwords; 4) if one written form has the same or similar pronunciation in the SL and BL, the role of orthography is minimal; 5) the BL native phonotactics also has a significant impact on the surface form of the loanword. Its application is unconditional and always prioritize other types of constraints, such as orthographic, perceptual and 
phonological constraints, in the OT analysis. Even though the output sounds similar to the input, it will still be ruled out in the selection of the optimal output if it has the illicit sound structures according to the BL phonology. The ill-formed output needs to modify its syllabic structures until it meets all the requirements of the BL phonological grammar.

\section{Acknowledgement}

The author thanks all the participants joined in this study. The study was funded by China Scholarship Council (grant number: CSC202006170075).

\section{References}

Boersma, P. \& Hamann, S. (2009). Loanword adaptation as first-language phonological perception. In: Andrea Calabrese \& Leo Wetzels (eds.) Loan Phonology. Amsterdam: Benjamins, 11-53.

Calabrese, A., \& Wetzels, L. (Eds.). (2009). Loan phonology. Amsterdam: John Benjamins Publishing Company.

Chang, J. C. (2013). Perceptual and phonotactic effects in loanword adaptation: English postvocalic stops in Taiwan MC. Journal of the Acoustical Society of America, 134(5), 4245. https://doi.org/10.1121/1.4831609.

Chen, Y., \& Lu, Y.-A. (2020). Variation in loanword adaptation: A case from MC Chinese. Second Language Research.

Cheng, C.C. (1973). A Synchronic Phonology of Mandarin Chinese. The Hague: Mouton.

Daland, R., Oh, M., \& Kim, S. (2015). When in doubt, read the instructions: Orthographic effects in loanword adaptation. Lingua, 159, 70-92. https://doi.org/10.1016/j.lingua.2015.03.002.

Detey, S. \& Nespulous, J. L. (2008). Can orthography influence second language syllabic segmentation? Japanese epenthetic vowels and French consonantal clusters. Lingua, 118(1), 66-81.

Duanmu, S. (2007). The phonology of standard Chinese. New York: Oxford University Press.

Hamann, S., Colombo, I.E. (2017). A formal account of the interaction of orthography and perception. Nat Lang Linguist Theory, 35, 683-714. https://link.springer.com/article/10.1007/s11049-0179362-3.

Hsieh, F. F. (2014). Loanword phonology and Chinese loanwords studies. Contemporary Linguistics, 16(3), 358-378.

Kang, Y. (2013). Loanwords. Oxford Bibliographies: Linguistics.

Kang, Y. (2009). English /z/in 1930s Korean. In: Potter, D., Storoshenko, D.R. (Eds.), The Simon Fraser University Working Papers in Linguistics 2 (Proceedings of the 2nd International Conference on East Asian Linguistics).

Kenstowicz, M. (2007). Salience and similarity in loanword adaptation: a case study from Fijian. Language Sciences, 29(2-3), 316-340. https://doi.org/10.1016/j.langsci.2006.12.023.

Keyser S. \& Stevens K. (2006). Enhancement and overlap in the speech chain. Language, 82, 33-63.

Kwon, H. (2017). Language experience, speech perception and loanword adaptation: Variable adaptation of English word-final plosives into Korean. Journal of Phonetics, 60, 1-19. https://doi.org/10.1016/j.wocn.2016.10.001. 
Lee, W. S., \& Zee, E. (2003). Standard Chinese. Journal of the International Phonetic Association, $33(1), 109-112$.

Lin, Y. H. (2008). Variable vowel adaptation in Standard MC loanwords. Journal of East Asian Linguistics, 17(4), 363. https://www.jstor.org/stable/4420249.

Li, Y. W. (1989). Auto-segmental Treatment of Segmental Process in Chinese Phonology. Ph. D dissertation, The university of Texas at Austin.

Ma, Q. W. (2008). Optimality Theory. Shanghai: Shanghai educational press.

Miao, R. Q. (2005). Loanword Adaptation in Mandarin Chinese: Perceptual, Phonological and Sociolinguistic Factors. Ph.D diss., Stony Brook University, New York, US.

Mou, X. (2006). Nasal codas in Standard Chinese: a study in the framework of the distinctive feature theory (Doctoral dissertation, Massachusetts Institute of Technology).

Paradis, C., \& LaCharité, D. (2008). Apparent phonetic approximation: English loanwords in old Quebec French. Journal of Linguistics, 44(1), 87-128. https://www.jstor.org/stable/40058029.

Peperkamp, S., Vendelin, I., \& Nakamura, K. (2008). On the perceptual origin of loanword adaptations: experimental evidence from Japanese. Phonology, 25(1), 129-164. https://www.jstor.org/stable/40213355.

Peperkamp, S., \& Dupoux, E. (2003). Reinterpreting loanword adaptations: the role of perception. In Proceedings of the 15th international congress of phonetic sciences, 367, p. 370.

Pulleyblank, E. G. 1983. Vowelless Chinese? An application to the three tried theory of syllable structure to Pekingese. Paper presented for the XVI International Conference on Sino-Tibetan Languages and Linguistics at University of Washington.

Silverman, D. (1992). Multiple scansions in loanword phonology: evidence from Cantonese. Phonology, 9(2), 289-328. https://www.jstor.org/stable/4420058.

Stevens K. \& Keyser S. (1989). Primary features and their enhancements in consonants. Language, 65, 81-106. https://www.jstor.org/stable/414843.

Yip, M. (2006). The symbiosis between perception and grammar in loanword phonology. Lingua, 116(7), 950-975. https://doi.org/10.1016/j.lingua.2005.05.007.

Zsiga, E. C. (2013). The sounds of language: An introduction to phonetics and phonology. New York: John Wiley \& Sons.

\section{AUTHOR BIODATA}

Wei Wang is a PhD candidate, with his major in linguistics and applied linguistics, at College of Humanities, Jilin University, China. He received his master degree of arts in linguistics at Department of Linguistics, The University of Hong Kong. His field of study is loanword phonology, phonologyphonetics interface, sociolinguistics, L2 acquisition, and foreign language teaching. 